\title{
Trombosis múltiple con afectación coronaria nativa secundaria a trombocitopenia inducida por heparina
}

\author{
Multiple thrombosis with native coronary involvement secondary to heparin-induced \\ thrombocytopenia
}

\author{
Francisco de-la-Cuerda1, Pablo Díez-Villanueva ${ }^{*}$, Jorge Salamanca ${ }^{1}$, Natalia Acedo-Domínguez², \\ Esther González y y Fernando Alfonso ${ }^{1}$ \\ ${ }^{1}$ Servicio de Cardiología; ${ }^{2}$ Servicio de Hematología. Hospital Universitario de la Princesa, Madrid, España
}

La trombocitopenia inducida por heparina $(\mathrm{TIH})$ es una complicación poco frecuente del tratamiento anticoagulante con heparina, secundaria a la formación de anticuerpos anti-PF4/heparina (complejo heparina-factor plaquetario 4) que lleva al desarrollo de fenómenos trombóticos paradójicos ${ }^{1,2}$. El diagnóstico de esta entidad se basa en la demostración de anticuerpos IgG anti-PF4/heparina en un contexto clínico de probabilidad intermedia/alta (4 o más puntos según la escala de 4T). Su tratamiento debe instaurarse ante la sospecha clínica, con interrupción inmediata de la heparina y administración de fármacos anticoagulantes alternativos $^{3,4}$. Aunque las trombosis relacionadas con este fenómeno son más frecuentes en el área venosa, se han descrito también episodios arteriales, incluso en el territorio coronario ${ }^{5}$.

Se presenta el caso de un paciente de 62 años con antecedente de dislipemia bajo tratamiento con atorvastatina y aneurisma de la aorta abdominal, intervenido en fecha reciente con implante de endoprótesis aórtica (Endurant ${ }^{\circledR} 25 \mathrm{~mm}$ ), que 10 días antes del alta hospitalaria solicitó atención médica domiciliaria por dolor torácico central opresivo intenso. En la primera valoración se obtuvo un electrocardiograma de 12 derivaciones que mostró elevación del segmento ST inferior, por lo que el paciente se trasladó al centro de los autores ante la sospecha de infarto agudo de miocardio (IAM). Se llevó a cabo una coronariografía urgente, que reveló ectasia coronaria difusa con un gran defecto de repleción en la arteria descendente anterior (ADA) a nivel proximal, consistente con trombosis no oclusiva, y una oclusión trombótica total (TIMI 0) en la arteria coronaria derecha (ACD) media, que era un vaso aneurísmico (Fig. 1A-B). El intervencionismo percutáneo en la ACD resultó ineficaz, a pesar de la tromboaspiración y múltiples insuflaciones del balón, y se concluyó el procedimiento con un flujo final TIMI II.

En la Unidad de Cuidados Cardíacos Agudos se confirmó una trombocitopenia grave ( 47,000 plaquetas/ $\mu \mathrm{L})$ de nueva aparición. Debido al antecedente de operación vascular 10 días antes (con cifras plaquetarias previas de 138,000 plaquetas $/ \mu \mathrm{L}$ y posterior recuento cinco días tras la intervención de 108,000 plaquetas $/ \mu \mathrm{L}$ ) con exposición a heparina no fraccionada a dosis de $1 \mathrm{mg} / \mathrm{kg}$ de peso durante la intervención $(80 \mathrm{mg})$, y ante la ausencia de otras causas que justificaran dicha trombocitopenia, se planteó la posibilidad de TIH (alto riesgo clínico con 6 puntos en la escala 4T). Se inició tratamiento con fondaparinux a dosis bajas $(2.5 \mathrm{mg}$ al día por vía subcutánea) por recomendación del Servicio de Hematología y se obtuvo muestra de sangre para estudio de anticuerpos anti-PF4/heparina, cuyo resultado fue positivo y confirmó el diagnóstico.
Correspondencia:

*Pablo Díez-Villanueva

E- mail: pablo_diez_villanueva@ hotmail.com
Disponible en internet: 09-03-2020 Arch Cardiol Mex. 2020;90(3) www.archivoscardiologia.com 1405-9940/@ 2020 Instituto Nacional de Cardiología Ignacio Chávez. Publicado por Permanyer. Este es un artículo open access bajo la licencia CC BY-NC-ND (http://creativecommons.org/licenses/by-nc-nd/4.0/). 


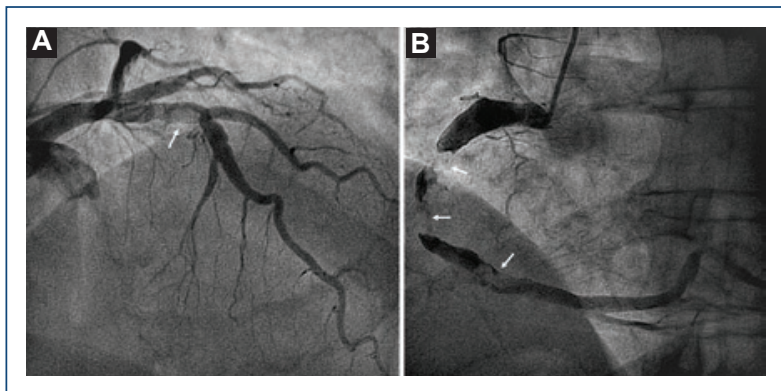

Figura 1. A: Hallazgos por angiografía en el árbol coronario izquierdo B: Coronaria derecha. Las flechas señalan amplios defectos de repleción indicativos de trombosis intracoronaria.

Con posterioridad, el paciente permaneció estable desde el punto de vista cardiológico, sin desarrollar insuficiencia cardíaca ni episodios arrítmicos. En las primeras 24 horas, el paciente comenzó con fiebre y dolor abdominal a nivel del flanco izquierdo de difícil control sintomático, por lo que se solicitó estudio de imagen abdominal mediante tomografía computarizada, que diagnosticó infarto esplénico (Fig. 2), así como trombosis de un radical venoso de la vena suprahepática media. Además, se identificó un aumento del perímetro del miembro inferior izquierdo con elevación del calor local y eritema de éste. El estudio Doppler de miembros inferiores demostró otro episodio trombótico en un ramo venoso perforante muscular. Dada la persistencia de la fiebre y el aislamiento en sangre de grampositivos ( $P$. acnes), se realizó una TEP-TAC que delineó un defecto de perfusión segmentario en el lóbulo superior derecho consistente con embolia pulmonar, y se descartó un proceso infeccioso en el material protésico intraaórtico. Ante estos hallazgos se incrementó la dosis administrada de fondaparinux hasta $7.5 \mathrm{mg}$ al día por vía subcutánea, sin nueva recurrencia de episodios tromboembólicos, y recuperación progresiva de cifras plaquetarias hasta $159,000 / \mu \mathrm{L}$ (la cifra más baja registrada fue de 32,000 plaquetas $/ \mu \mathrm{L}$ ). Por último, el paciente egresó con acenocumarol y tratamiento antiagregante con ácido acetilsalicílico $(100 \mathrm{mg}$ al día). Se indicó seguimiento posterior en consultas de los Servicios de Cardiología y Hematología, sin notificación de nuevos episodios isquémicos y con retiro de la anticoagulación oral luego de 12 meses de tratamiento.

La TIH es un fenómeno inmunológico reconocido con una incidencia variable de 0.5 a $5 \%$ de los pacientes expuestos, en función del tipo y la dosis de heparina

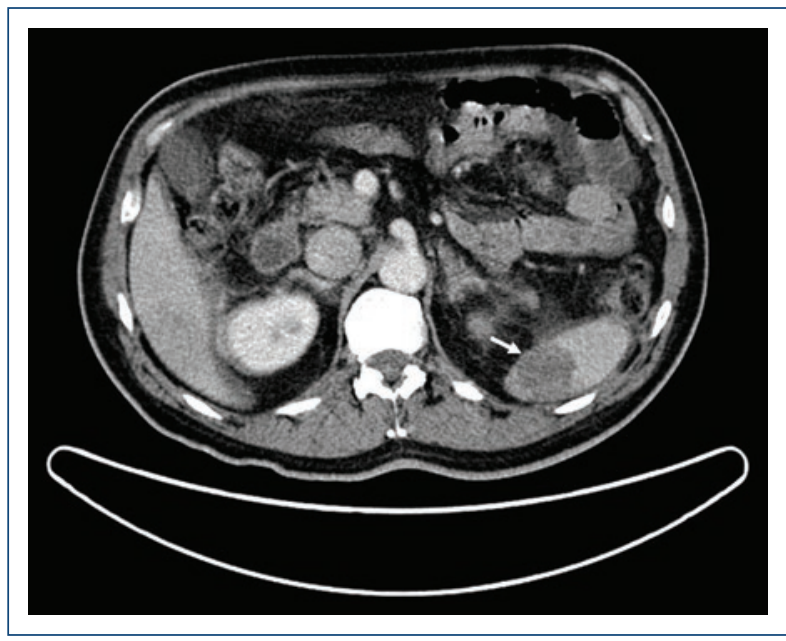

Figura 2. Hallazgos intraabdominales por tomografía axial computarizada que demuestran infarto esplénico (flecha).

suministrada ${ }^{3}$. Los anticuerpos anti-PF4/heparina activan la agregación plaquetaria y favorecen el desarrollo de fenómenos trombóticos venosos y arteriales con consumo de plaquetas y al final trombocitopenia ${ }^{3}$. Los episodios trombóticos coronarios son muy raros y en particular se han descrito casos en pacientes con intervencionismo previo, tanto percutáneo como quirúrgico ${ }^{5}$ (es excepcional la afectación del árbol coronario nativo). Además, la incidencia de TIH en pacientes expuestos a heparina en el contexto de una operación vascular es baja, a pesar de que el desarrollo de anticuerpos en el postoperatorio no es infrecuente ${ }^{1,6}$. En este caso destaca la afectación a varios niveles del árbol coronario con abundante contenido trombótico en un paciente con exposición previa a heparina y sin enfermedad coronaria arteriosclerótica conocida, en el que la presencia de ectasia coronaria pudo favorecer la trombosis in situ. Además, se demostraron múltiples fenómenos tromboembólicos en áreas distintas. En este paciente, el tratamiento con fondaparinux subcutáneo a dosis altas logró estabilizar el cuadro clínico, con recuperación de las cifras plaquetarias y sin recurrencias.

\section{Financiamiento}

Ninguno.

\section{Conflicto de intereses}

Los autores declaran no tener ningún conflicto de intereses. 


\section{Responsabilidades éticas}

Protección de personas y animales. Los autores declaran que los procedimientos seguidos se conformaron a las normas éticas del comité de experimentación humana responsable y de acuerdo con la Asociación Médica Mundial y la Declaración de Helsinki.

Confidencialidad de los datos. Los autores declaran que han seguido los protocolos de su centro de trabajo sobre la publicación de datos de pacientes.

Derecho a la privacidad y consentimiento informado. Los autores han obtenido el consentimiento informado de los pacientes o sujetos referidos en el artículo. Este documento obra en poder del autor de correspondencia.

\section{Bibliografía}

1. Martel N, Lee J, Wells PS, Engström G. Risk for heparin-induced thrombocytopenia with unfractionated and low-molecular-weight heparin thromboprophylaxis: a meta-analysis. Blood 2005;106:2710-2715.

2. Gallagher MJ, Ajluni SC, Almani SL. Coronary artery stent thrombosis associated with heparin-induced thrombocytopenia: case report and review of the literature. J Interv Cardiol. 2005;18:131-137.

3. Cruz-González I, Sánchez-Ledesma M, Sánchez PL, Jang IK. Heparin-induced thrombocytopenia. Rev Esp Cardiol. 2007;60:1071-1082.

4. Cuker A, Arepally GM, Chong BH, Cines DB, Greinacher A, Gruel Y, et al. American Society of Hematology 2018 guidelines for management of venous thromboembolism: heparin-induced thrombocytopenia. Blood Adv. 2018;2:3360-3392.

5. Almeqdadi M, Aoun J, Carrozza J. Native coronary artery thrombosis in the setting of heparin-induced thrombocytopenia: a case report. European Heart Journal-Case Reports 2018;2:1-5.

6. Lindhoff-Last E, Eichler P, Stein M, Plagemann J, Gerdsen F, Wagner $\mathrm{R}$, et al. A prospective study on the incidence and clinical relevance of heparin-induced antibodies in patients after vascular surgery. Thromb Res. 2000;97:387-393. 